\title{
Polyamine Participation in the Maturation of Glycoprotein Fucosylation, but not Sialylation, in Rat Small Intestine
}

\author{
MARIE-CLAIRE BIOL-N'GARAGBA, SANDRINE GRECO, PASCAL GEORGE, \\ IRÈNE HUGUENY, AND PIERRE LOUISOT \\ INSERM Unit U189-SDI CNRS, Department of Biochemistry, Faculty of Medicine Lyon-Sud, Claude \\ Bernard Lyon-1 University, Oullins, France
}

ABSTRACT

\begin{abstract}
The aim of this study was to determine the role of polyamines in the diet-related maturation of the intestinal glycoprotein glycosylation during postnatal development in the rat. The activity of $\alpha$-2,6-sialyltransferase and the sialylated forms of glycoproteins in the intestinal brush-border membranes were found to decrease considerably after weaning, in parallel with the intestinal level of putrescine. By contrast, the activity of $\alpha-1,2-$ fucosyltransferases, the mRNA levels for two $\alpha$-1,2-fucosyltransferase genes, FTA and FTB, and the fucosylated forms of glycoproteins all increased after weaning, in parallel with the levels of spermidine and spermine. These results suggest a possible role of polyamines in the evolution of glycosylation. The treatment of suckling rats with spermidine or spermine reproduced the high intestinal levels of these polyamines corresponding to those normally found after weaning. After these treatments, a rise in the activity of the $\alpha-1,2$-fucosyltransferase was observed, associated with a fall in $\alpha$-L-fucosidase activity. The $\alpha$-1,2-fucosyltransferase FTB gene was found to be regulated at the transcriptional level, but not by its inhibitor, fuctinin. The result of these variations was the precocious appearance of several $\alpha$-1,2-fucoproteins, which are normally found in brushborder membranes after weaning. The treatment of suckling rats with putrescine, which induced only a transitory rise in intestinal
\end{abstract}

putrescine, had a similar but weaker effect on the fucosylation process than spermidine or spermine, and treatment with ornithine was ineffective. $\alpha-2,6$-Sialylation was not affected by any of the treatments. Spermidine and spermine turned out to be more effective than putrescine for intestinal glycoprotein fucosylation, but did not affect their sialylation. Spermidine and spermine, whose intestinal levels where found to increase at weaning time, may have been partly responsible for the natural evolution of the intestinal glycoprotein fucosylation that occurred during this period. (Pediatr Res 51: 625-634, 2002)
O, ornithine
$\mathbf{P}$, putrescine
Sd, spermidine
Sm, spermine
NacSd, $N$-acetylspermidine
NacSm, $N$-acetylspermine
SNA, Sambuscus nigra lectin
UEA-I, Ulex europeus lectin
$\boldsymbol{F T A}$ and $\boldsymbol{F T B}, \alpha-1,2$-fucosyltransferase genes
G3PDH, glyceraldehyde-3-phosphate dehydrogenase

The rat small intestine is immature until the end of the third week of life, when the weaning period begins. Intestinal maturation is associated with morphologic changes, an increase in mucus production, immunologic adaptation to new microbial and nutritional antigenic contents (1), and digestive adaptation to new nutriments (2).

Two types of glycoproteins play important functional roles in the small intestine. Mucins (secreted by the goblet cells) are

Received August 23, 2000; accepted July 27, 2001.

Correspondence and reprint requests: M-C. Biol, Ph.D., Unité INSERM U189-SDI CNRS, Département de Biochimie, Faculté de Médecine Lyon-Sud, BP 12, 69600 Oullins, France; e-mail: biol@lyon-sud.univ-lyon1.fr

Supported by the Institut National de la Santé et de la Recherche Médicale (INSERM), the Center National de la Recherche Scientifique (CNRS), and the Claude Bernard Lyon-1 University. different in composition between neonatal and mature rats, especially as regards their glycan chains (3). In the neonate, these changes may affect the permeability (4) and the barrier function of the intestine, and consequently may favor infections (5) and food allergies (6). At the apical enterocyte level, in the brush-border membranes, most of the digestive enzymes (lactase, sucrase, maltase, aminopeptidase, alkaline phosphatase) are glycoproteins whose activity changes a great deal at weaning time to enable the animal to cope with the adult solid diet (2). A shift from high sialylation (before weaning) to high fucosylation (after weaning) has been observed in the brushborder membrane glycoproteins (7-10), associated with a decrease in intestinal activity, and also in the mRNA level of $\alpha$-2,6-sialyltransferase on $N$-glycans (11), as well as an in- 
crease in fucosyltransferase activity $(12,13)$. We know that the active form of lactase is sialylated, and the inactive form fucosylated $(14,15)$, and also that the structure of lactase and sucrase glycan chains may be responsible for their integration into the apical membrane of the enterocyte $(14,16)$, but otherwise the role of the glycan chains in the biologic activity of these glycoproteins is largely unknown.

The development of the small intestine is regulated by, among other things, hormonal factors $(12,17-22)$ and maturation factors such as polyamines (23-26), which are found in milk and the postweaning diet, and are vital for the functioning and renewal of the gut epithelium. The role of polyamines in growth and differentiation is particularly important (27). Their oral administration to suckling rats induces many of the morphologic and biochemical modifications that characterize the intestinal postnatal maturation that begins at weaning (23-26, $28,29)$, which suggests that polyamines play a role in this process.

The aim of this study was to find out whether polyamines play a role in the maturation of glycoprotein glycosylation during postnatal development in rats. We first studied the developmental variations of $\alpha-1,2$-fucosyltransferase and its transcriptional regulation. We also studied the polyamine variations in the small intestinal mucosa in relation to polyamine consumption. We then investigated the possible role of the different polyamines (putrescine, spermidine, and spermine), and their precursor (ornithine), on the sialylation and fucosylation of glycoproteins in the small intestine of suckling rats, with respect to the content of the intestine polyamine.

\section{METHODS}

Animals, treatment, and milk collection. Immediately after birth, the pups were distributed as litters of 10 suckling male rats (Sprague-Dawley strain; IFFA CREDO, L'Arbresle, France), and maintained on a 12-h/12-h light-dark cycle at $21^{\circ} \mathrm{C}$. Dams and males (weaned at $19 \mathrm{~d}$ of age) were fed a commercial diet, Ico (UAR, Villemoisson-sur-Orge, France).

In the first experiment, starting when the rats were $10 \mathrm{~d}$ old (average weight, $25 \mathrm{~g}$ ), five pairs of pups from each litter were given similar amounts of polyamines as $10 \mu \mathrm{mol}(0.4 \mu \mathrm{mol} / \mathrm{g}$ body weight) of either ornithine, putrescine, spermidine, or spermine in water, or water alone, via oral ingestion, once a day for $4 \mathrm{~d}$. In the second experiment, also starting when the rats were $10 \mathrm{~d}$ old, pairs of pups received amounts of polyamines proportional to the consumption of each polyamine by the weaned rats $(30 \mu \mathrm{mol}$ of putrescine, $10 \mu \mathrm{mol}$ of spermidine, and $2 \mu \mathrm{mol}$ of spermidine per rat) once a day for $4 \mathrm{~d}$. To avoid stress, the polyamines were given directly by mouth using a syringe with a soft tip.

To study the changes in putrescine levels at different times after ingestion, 14-d-old suckling rats (average body weight, $30 \mathrm{~g}$ ) or 28-d-old weaned rats (average body weight, $90 \mathrm{~g}$ ) were given single oral doses of 10 and $30 \mu \mathrm{mol}$ of putrescine per rat, respectively. The animals were killed either $1,2,4,8$, 16 , or $24 \mathrm{~h}$ after the treatment. The effects of the different amounts of polyamines (between 0.04 and $4 \mu \mathrm{mol} / \mathrm{g}$ body weight), given to the 14-d-old and the 28-d-old rats, were investigated $4 \mathrm{~h}$ after the treatment.

To stimulate milk ejection, the rats were anesthetized and injected with $5 \mathrm{mU}$ of oxytocin per gram of body weight. Milk samples ( 250 to $700 \mu \mathrm{L}$ ) were collected by manual draft, put in cryotubes, and immediately frozen at $-180^{\circ} \mathrm{C}$, pending polyamine assays.

The protocols for the experiments were approved by the French Ministry of Agriculture and Forestry, Veterinary Department, Permit No. 69000581.

Cell fractionations. After decapitation and laparotomy, the small intestines of the rats (from the gastroduodenal junction to the ileocecal junction) were removed and flushed with ice-cold $9 \mathrm{~g} / \mathrm{L}$ saline solution. The mucosae were harvested with a glass slide, homogenized in $10 \mathrm{mM}$ Tris- $\mathrm{HCl}, 10 \mathrm{mM} \mathrm{KCl}, 10 \mathrm{mM}$ $\mathrm{MgCl}_{2}, 250 \mathrm{mM}$ sucrose, $\mathrm{pH}$ 7.4, buffer with a Potter-Elvehjem homogenizer $(5 \mathrm{~mL} / \mathrm{g}$ wet tissue) and centrifuged for $30 \mathrm{~min}$ at $30,000 \times g$ in a JA 14 rotor (J21 centrifuge, Bechman Coulter, Palo Alto, CA, U.S.A.). The supernatant was centrifuged at $4^{\circ} \mathrm{C}$ for $1 \mathrm{~h} 30 \mathrm{~min}$ at $150,000 \times \mathrm{g}$, which produced microsomes and cytosols. The brush-border membranes were prepared from the mucosae using the method of Kessler et al. (30). Depending on the age of the animals, one to three rats were used for the preparation of each subcellular fraction.

Protein determinations. Proteins were determined according to the method of either Lowry et al. (31) or Schaffner and Weissmann (32).

Polyamine determinations. The polyamine determinations were performed as previously described (33). Briefly, the small intestines (from the gastroduodenal junction to the ileocecal junction) were quickly removed and washed with $9 \mathrm{~g} / \mathrm{L}$ saline solution at $4{ }^{\circ} \mathrm{C}$. The intestinal mucosae were harvested with a glass slide and homogenized in deionized water at $4^{\circ} \mathrm{C}$. The homogenates were quickly frozen at $-180^{\circ} \mathrm{C}$ to avoid polyamine degradation by diamine and polyamine oxidases. Immediately before the polyamine determination, the samples of milk, commercial food, and intestinal mucosa were diluted in deionized water at $4^{\circ} \mathrm{C}$. An internal standard was added, and the proteins were discarded after precipitation. After derivatization with $1 \mathrm{mM} 9$-fluorenylmethyl chloroformate for $45 \mathrm{~s}$ at room temperature, the polyamines were separated by HPLC, as previously described (33), identified by their retention times, and quantified by comparison with standard concentration curves, using 1,6-hexanediamine as an internal standard.

Determination of diamine oxidase activity. The diamine oxidase activity was determined in reaction mixtures $(100 \mu \mathrm{L})$ containing $400-500 \mu \mathrm{g}$ of mucosa homogenate proteins in 100 $\mathrm{mM}$ sodium phosphate buffer, $\mathrm{pH} 7.2,250 \mu \mathrm{M}$ of a mixture of putrescine and ${ }^{14} \mathrm{C}$-putrescine (sp act, $4.1 \mathrm{GBq} / \mathrm{mol}$; PerkinElmer Life Science Products, Boston, MA, U.S.A.) with or without $10 \mathrm{mM}$ aminoguanidine, an enzyme inhibitor. Kinetic studies were performed for $5-60 \mathrm{~min}$ at $37^{\circ} \mathrm{C}$. The reactions were stopped with $100 \mu \mathrm{L}$ of $250 \mathrm{mM}$ putrescine and the addition of $2 \mathrm{~mL}$ of toluene. The labeled reaction products were extracted in the organic phase for $10 \mathrm{~min}$ at room temperature, followed by centrifugation at $5000 \times \mathrm{g}$ for 10 min. Radioactivity was determined using Emulsifier Scintillator Plus (Packard Instruments, Groningen, Netherlands.). The 
diamine oxidase activity was found by subtracting activity in the presence of aminoguanidine from activity in its absence, and determining the slope for the linear part of the curve.

Determination of glycosyltransferase activity. Gal- $\beta 1,4-$ GlcNAc was used as the oligosaccharide acceptor for the determination of $\alpha$-2,6-sialyltransferase activity on the $\mathrm{N}$ glycans (E.C.2.4.99.1). The reaction mixture contained 200$300 \mu \mathrm{g}$ of proteins (in $10 \mathrm{mM}$ Tris- $\mathrm{HCl}, 10 \mathrm{mM} \mathrm{KCl}, 10 \mathrm{mM}$ $\mathrm{MgCl}_{2}, \mathrm{pH} 7.4$, buffer), $3.5 \mathrm{mM}$ Gal- $\beta 1,4-G l c N A c, 10 \mathrm{mM}$ AMP, $0.50 \%$ Triton X-100, $4 \mu \mathrm{M}$ of a mixture of CMP- $N$ acetylneuraminic acid and $\mathrm{CMP}-{ }^{14} \mathrm{C}-\mathrm{N}$-acetylneuraminic acid (sp act, $10.1 \mathrm{GBq} / \mathrm{mmol}$; PerkinElmer). The incubations were carried out for $30 \mathrm{~min}$ at $30^{\circ} \mathrm{C}$, and the reactions were stopped with $500 \mu \mathrm{L}$ of $0.1 \mathrm{M} \mathrm{KCl}$ at $4^{\circ} \mathrm{C}$. After centrifugation, the radiolabeled products in the supernatants were separated by chromatography on HPTLC silica gel 60 plates using ethanol/ pyridine/n-butanol/acetic acid/ $\mathrm{H}_{2} \mathrm{O}(100 / 10 / 10 / 3 / 30)$ as migration solvent, then scraped after autoradiography. $\alpha-1,2-$ Fucosyltransferase activity (E.C.2.4.1.69) was determined with phenyl- $\beta$-D-galactopyranoside as the specific acceptor, in conditions previously described (33). In all cases, radioactivity was determined using the Emulsifier Scintillator Plus (Packard Instruments). Glycosyltransferase activity was obtained by subtracting the endogenous activity (determined without an exogenous acceptor).

RNA preparation and Northern analysis. Total RNA was isolated from small intestine mucosae by the guanidinium thiocyanate method of Chomczynski and Sacchi (34). Northern hybridization analyses were performed as previously described (33), using digoxigenin-labeled cRNA probes synthesized from fragments of cDNA encoding two $\alpha$-1,2-fucosyltransferase genes, FTA and FTB (35), inserted into a plasmid including a T7 promoter. The cDNA was provided by Dr. J. LePendu, University of Nantes. Control hybridizations were conducted with a digoxigenin-labeled G3PDH cRNA probe in the same way, once the membranes had been stripped. The relative $F T A, F T B$, and G3PDH mRNA levels were determined by densitometry with a BioRad GS-700 densitometer, with Molecular Analyst software (Bio-Rad, Hercules, CA, U.S.A.).

Enzyme activity in the fucosylation process. The activity of fuctinin, a fucosyltransferase inhibitor, was determined using partially purified $\alpha-1,2$-fucosyltransferase in a fraction semipurified from cytosol, as described previously (22). It was expressed as the quantity of proteins producing a $50 \%$ inhibition of fucosyltransferase activity. The synthesis of GDPfucose (guanosine diphosphoglucose) (by epimerasereductase) and its degradation (by pyrophosphatase) were studied in cytosols, and the reaction products were separated by HPLC as described previously (9). $\alpha$-L-Fucosidase activity was determined in cytosol, according to Kobata's method (36).

Detection of glycoproteins in the brush-border membranes. Proteins from the intestinal brush-border membranes were resolved by electrophoresis on a $0.1 \%$ SDS, $7.5 \%$ gel acrylamide, and then electrotransferred to a nitrocellulose membrane (Schleicher-Schüll, Dassell, Germany). $\alpha$-2,6-Sialic acid and $\alpha-1,2$-fucose residues in glycoproteins were detected in 50 $\mathrm{mM}$ Tris, $150 \mathrm{mM} \mathrm{NaCl}, 0.1 \%$ Tween 20 , using respectively 1 $\mu \mathrm{g} / \mathrm{mL}$ of a digoxigenin-labeled lectin from Sambucus nigra
(SNA; Roche Diagnostics) and $0.6 \mu \mathrm{g} / \mathrm{mL}$ of a biotin-labeled lectin from Ulex europeus (UEA-I; Sigma Chemical Co.Aldrich Chimie, Saint-Quentin-Fallavier, France), as described previously (9). Digoxigenin was recognized with $750 \mathrm{mU} / \mathrm{mL}$ of an alkaline phosphatase-labeled antidigoxigenin antibody and biotin, with $1 \mathrm{U} / \mathrm{mL}$ alkaline phosphatase-labeled streptavidin (both from Roche Diagnostics). Alkaline phosphatase was revealed with $1.8 \mathrm{mM}$ nitro-blue tetrazolium and $0.5 \mathrm{mM}$ 5-bromo-4-chloro-3-indolylphosphate.

Statistical analysis. The results were expressed as mean \pm SEM. Between two groups, the means were compared by the unpaired $t$ test or the Mann-Whitney $U$ test. For comparison among more than two groups, a one-factor ANOVA was used, and the means were compared by the Newman-Keuls test.

\section{RESULTS}

The polyamine content of milk and commercial diet, and rat polyamine consumption. In milk, we found that the spermidine level was consistently the highest (Fig. $1 A$ ). Spermidine and spermine levels increased significantly at the end of the lactation period (18th day), that of putrescine remained low, and quite steady, during the same period. With the commercial diet (Ico), the levels of putrescine, spermidine, and spermine were significantly higher (respectively approximately 65-, 1.5-, and 6-fold) than those found in the milk at $14 \mathrm{~d}$ (Fig. 1B). $\mathrm{N}$-Acetylspermidine and $\mathrm{N}$-acetylspermine levels were very low both in the milk and the commercial diet (data not shown).

The 14-d-old suckling rats (weighing approximately $30 \mathrm{~g}$ ) were consuming approximately $6 \mathrm{~mL}(6.3 \mathrm{~g})$ of milk per day, so that their average daily polyamine consumption was 20 nmol putrescine, $360 \mathrm{nmol}$ spermidine, and $16 \mathrm{nmol}$ spermine. In the 28-d-old weaned rats (weighing approximately $90 \mathrm{~g}$ ), which ate between 18 and $20 \mathrm{~g}$ of Ico per day, the average amounts of polyamine ingested per day were $4300-4900 \mathrm{nmol}$ putrescine, 1600-2000 nmol spermidine, and 290-320 nmol
A

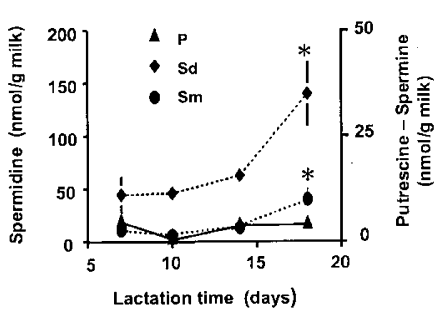

B

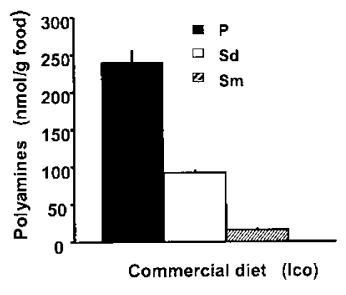

Figure 1. Polyamine levels in milk and the commercial diet. Polyamine contents (nmol/g) were determined by HPLC. $P$, putrescine; $S d$, spermidine; $S m$, spermine. $A$, milk collected between the 7 th and the 18 th days of lactation. $B$, commercial diet (Ico). For the milk, the values of eight independent determinations at each lactation time are reported as the mean \pm SEM. The results were submitted to a one-factor ANOVA, and the means were compared by the Newman-Keuls test. ${ }^{*} p<0.005$, significantly different values from the others. For Ico, values are given as the means for 11 determinations. The means for Ico were compared with the means for milk by the Newman-Keuls test. For putrescine and spermine, the values were significantly higher for Ico than for milk, irrespective of lactation time $(p<0.050)$. For spermidine, the values for Ico were significantly higher than those for milk between the 7 th and the 14th days of lactation $(p<0.050)$. 
spermine. In terms of amount per gram of body weight, the amounts of polyamines ingested daily were higher for the 28-d-old rats than for the 14-d-old rats (around 70-fold for putrescine, 1.7-fold for spermidine, and 7-fold for spermine).

Developmental changes in polyamine levels in the small intestine. Spermidine was the polyamine that was found to have the highest concentration in the small intestinal mucosae, irrespective of age (Fig. 2). Spermidine levels increased sharply after weaning. Spermine levels also increased after weaning, but less strongly. By contrast, intestinal putrescine levels were low throughout, and actually decreased significantly after weaning. At all ages, $N$-acetylspermidine and $\mathrm{N}$-acetylspermine levels were very low $(0.01-0.04 \mathrm{nmol} / \mathrm{mg}$ protein).

Changes in polyamine levels in immature and mature rat small intestines: at several times after treatment with putrescine, and at a given time after treatment with different amounts of putrescine. First, both the 14-d-old and the 28-dold rats were given comparable amounts of putrescine (as a single ingestion of $0.4 \mu \mathrm{mol} / \mathrm{g}$ body weight), and the polyamine levels in their small intestinal mucosae were measured at different times. In the intestinal mucosae of the 14-d-old rats, the putrescine level increased progressively, reaching a maximum $4 \mathrm{~h}$ after the treatment (increase factor, 6.4); then falling back to the basal level (Fig. 3). By contrast, in the intestinal mucosae of the 28-d-old rats, the level did not increase significantly. Second, 14-d-old and 28-d-old rats were treated with increasing amounts of putrescine (between 0.04 and $4 \mu \mathrm{mol} / \mathrm{g}$ body weight), and the putrescine levels in the intestinal mucosae were measured $4 \mathrm{~h}$ after ingestion. In the mucosae of the 14-d-old rats, the putrescine level rose between 0.04 and 0.8 $\mu \mathrm{mol} / \mathrm{g}$ body weight, leveling up to approximately 6 -fold the basal level found for the control rats, then it plateaued (data not

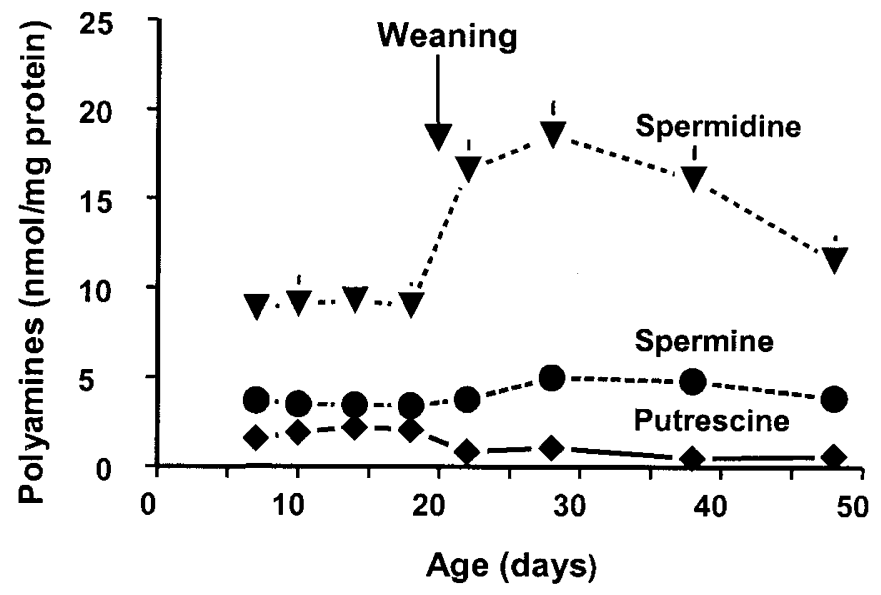

Figure 2. Developmental changes in intestinal polyamine levels. The rats were weaned with Ico at $19 \mathrm{~d}$ of age. The polyamine levels in the small intestine mucosae were determined by HPLC. One intestine was used for each determination. Results are mean \pm SEM for 10 independent determinations at each age. The results were submitted to a one-factor ANOVA, and the means were compared by the Newman-Keuls test. For spermidine, all the values obtained after weaning were significantly higher than those obtained before weaning $(p<0.050)$. The opposite result was obtained for putrescine. For spermine, significant differences were observed, on the one hand, between 14- and 18-d-old rats, and, on the other hand, 28- or 38 day-old rats $(p<0.050)$.

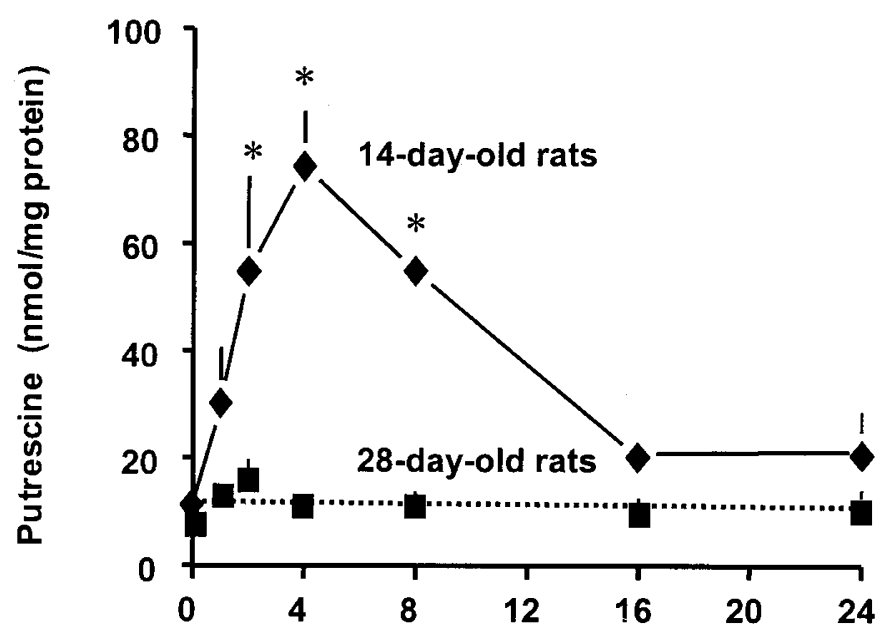

Time after putrescine ingestion (hours)

Figure 3. Changes in intestinal putrescine level in the small intestine at several times after ingestion. The $14-\mathrm{d}$-old and 28 -d-old rats were given a single oral dose of putrescine ( $0.4 \mu \mathrm{mol}$ of putrescine/g body weight), i.e. 10 $\mu \mathrm{mol}$ per rat for the suckling rats and $30 \mu \mathrm{mol}$ per rat for the weaned rats. All the rats were killed $2,4,8,16$, or $24 \mathrm{~h}$ after ingestion. Putrescine levels were expressed as mean $\pm \mathrm{SEM}$, with four independent determinations. The results were submitted to a one-factor ANOVA, and the means obtained at each age were compared by the Newmann Keuls test: ${ }^{*} p<0.010$, significantly different values from the others.

shown). The 28-d-old weaned rats, on the other hand, showed no significant effect, irrespective of the dosage of putrescine. No significant conversion of putrescine to spermidine or spermine was observed (data not shown).

Intestinal diamine oxidase activity was significantly lower for the 28-d-old rats $\left(387 \pm 41 \mathrm{pmol} \cdot \mathrm{mg}\right.$ protein ${ }^{-1} \cdot \mathrm{min}^{-1}$, $n=6 ; p<0.002)$ than for the 14-d-old rats $(693 \pm 59$ $\mathrm{pmol} \cdot \mathrm{mg}$ protein ${ }^{-1} \cdot \min ^{-1} ; n=6$ ).

Developmental changes in glycosyltransferase activity and glycoproteins in the brush-border membrane. $\alpha-2,6-$ Sialyltransferase activity fell significantly in the small intestines of the weaned rats after the 22nd day (Fig. 4A), and the $\alpha$-2,6-sialoprotein amount detected in the brush-border membrane decreased in parallel with this enzyme activity (Fig. $4 B$ ).

Figure $5 A$ shows that membrane-bound $\alpha-1,2$-fucosyltransferase activity rose significantly immediately after weaning, and similar results were observed for the soluble activity (not shown). $\alpha$-1,2-Fucosyltransferase activity was regulated at transcriptional level. The mRNAs levels of this enzyme's two genes (FTA and FTB) increased after weaning, in parallel with the activity of the enzyme (Fig. $5 B$ ). This was also illustrated by the ratio of mRNA for FTA and FTB to that for the stable control G3PDH, which increased significantly after weaning (Fig. 5C).

Effects of polyamines or their precursor on the intestinal polyamine contents of suckling rats. To assess the possible role of polyamines on the intestinal maturation of glycoprotein glycosylation in the rat small intestine, we attempted to produce, in the intestinal mucosae of the suckling rats, levels of polyamines (particularly spermidine and spermine) close to 


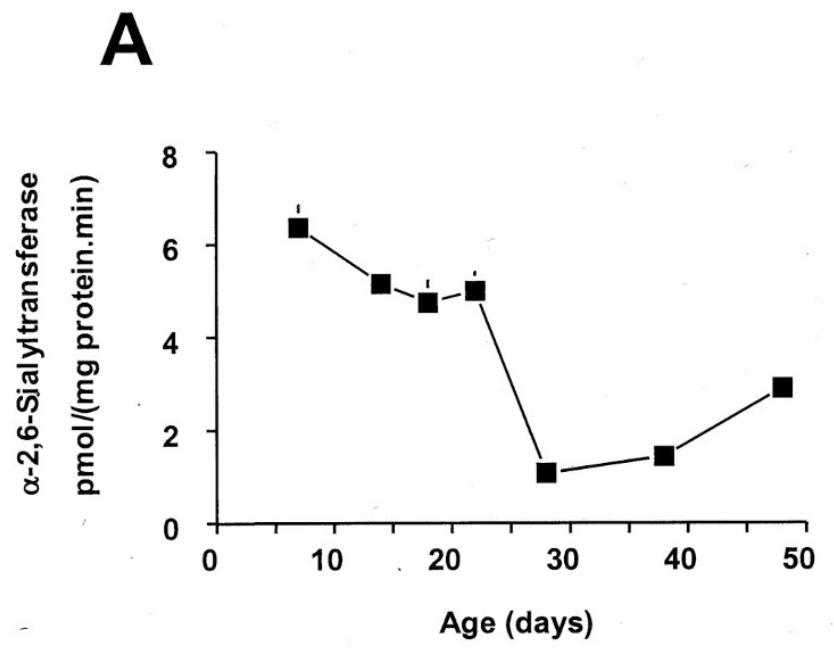

B

\section{$\alpha-2,6$-sialoproteins}

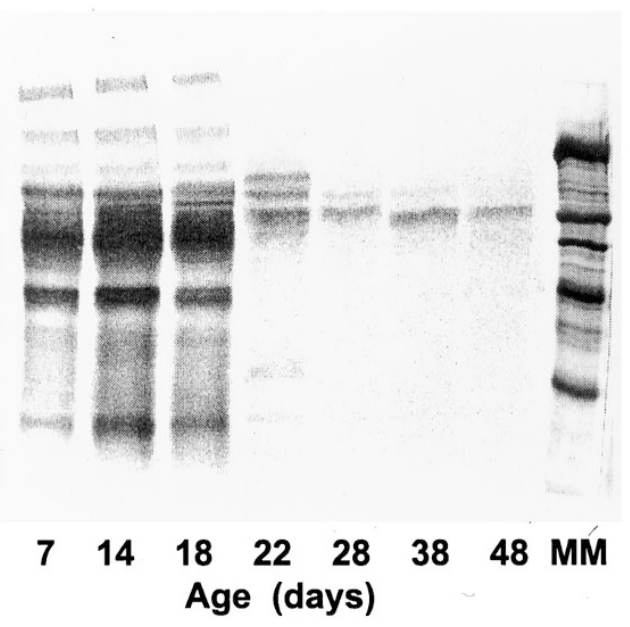

$\mathrm{kDa}$

200

116

97

66

45

Figure 4. Developmental changes in the $\alpha$-2,6-sialylation process. The animals were weaned at $19 \mathrm{~d}$ of age with Ico. $A, \alpha$-2,6-sialyltransferase activity in microsomal membranes. Values are mean $\pm \operatorname{SEM}(n=4)$. The results were submitted to a one-factor ANOVA, and the means were compared by the Newman-Keuls test. Values for the weaned rats between 28 and $48 \mathrm{~d}$ of age, were significantly lower than values for all the other groups $(p<0.050)$. $B$, detection of $\alpha$-2,6-sialic acid residues in brush-border membrane glycoproteins of 7- to 48-d-old rats, after SDS-PAGE (12 $\mu \mathrm{g}$ of proteins/lane) and transfer onto a nitrocellulose membrane, using the specific lectin of Sambucus nigra (SNA). MM, molecular mass control.

those found in the mucosae of the weaned rats. This was done by repeated oral ingestions of the different polyamines.

In the first experiment, the suckling rats were treated once a day for $4 \mathrm{~d}$, starting at $10 \mathrm{~d}$ of age, with similar amounts of the different polyamines or ornithine $(10 \mu \mathrm{mol}$ per rat), these quantities being close to those used in other studies $(24,26,28$, $37)$. Under these conditions, the putrescine, spermidine, and spermine amounts ingested daily by the 14-d-old rats were respectively $2-, 6$-, and 30 -fold those ingested by 28 -d-old rats

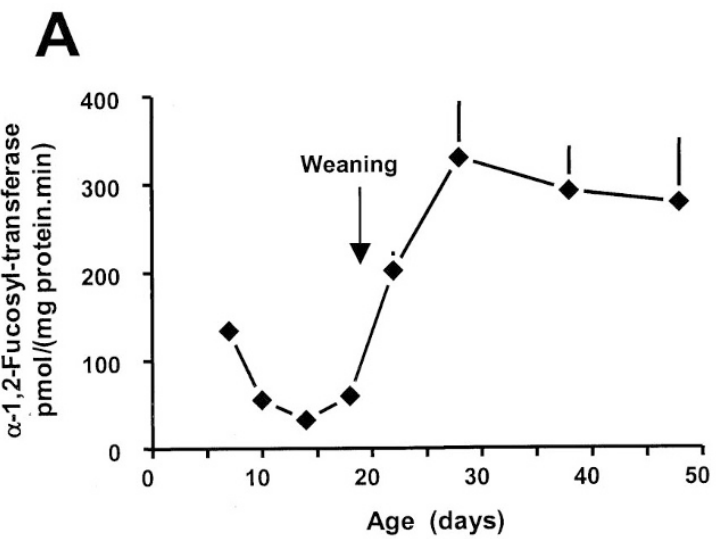

B

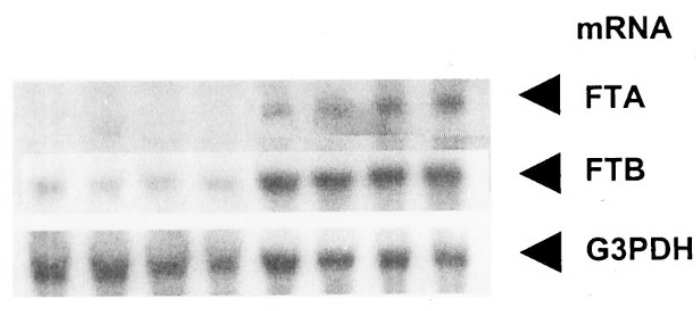

Age : $\begin{array}{llllllllll}7 & 10 & 14 & 18 & 22 & 28 & 38 & 48 & \text { (days) }\end{array}$

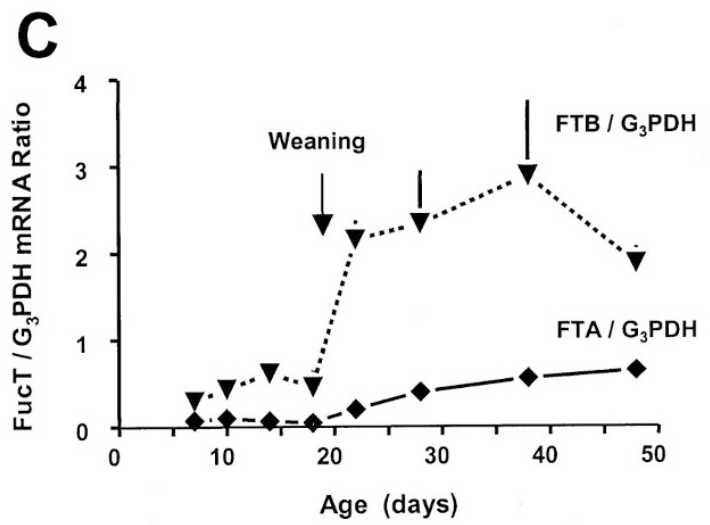

Figure 5. Developmental changes in $\alpha-1,2$-fucosyltransferase activity and mRNA levels. The animals were weaned at $19 \mathrm{~d}$ of age with Ico. $A$, membranebound $\alpha-1,2$-fucosyltransferase activity. Values are mean $\pm \operatorname{SEM}(n=5)$. The results were submitted to a one-factor ANOVA, and the means were compared by the Newman-Keuls test. Values for all the weaned rats (22-48 d of age) were significantly higher than for the $10-18$ day-old rats $(p<0.050)$. B, Northern blots for the determination of the mRNA of the two $\alpha-1,2-$ fucosyltransferase genes $F T A$ and FTB. Thirty micrograms of total RNA (for each age) was separated by electrophoresis, then blotted onto a nylon membrane. Hybridization was performed with FTA or FTB cRNA digoxigeninlabeled probes, and control hybridization with a G3PGH cRNA digoxigeninlabeled probe. $C$, semiquantitative estimation of $F T A$ and $F T B$ mRNA. The relative mRNA levels of the FTA and FTB genes were taken as their ratios to the mRNA of G3PDH used as a control (mean \pm SEM; $n=3$ ). The results were submitted to a one-factor ANOVA, and the means were compared by the Newman-Keuls test. The values obtained for the weaned rats were significantly higher than for the suckling rats $(p<0.050)$.

fed on Ico. As shown in Figure 6, in small intestines of 14-d-old spermidine- and spermine-treated rats, the respective levels of the spermidine or spermine increased significantly 
compared with those of the control rats (1.5-fold for spermidine and 1.7-fold for spermine), reaching levels close to those of the 28-d-old rats. In the spermidine-treated rats, moreover, not only had the spermidine level increased, but also those of putrescine and $N$-acetylspermidine. By contrast, the polyamine levels did not change as a result of treatment with putrescine (Fig. 6) and ornithine (not shown).

In the second experiment, the suckling rats were given different amounts of each polyamine, once a day for $4 \mathrm{~d}$ (starting at $10 \mathrm{~d}$ of age), but in amounts proportional to the consumption of these polyamines by the weaned rats. $\mathrm{Pu}$ trescine was given at $30 \mu \mathrm{mol}$ per rat, spermidine at $10 \mu \mathrm{mol}$ per rat, and spermine at $2 \mu \mathrm{mol}$ per rat, corresponding to 5-6 times the amounts ingested by the 28 -d-old rats and twice as much as those ingested by 48 -d-old adult rats. In the rats that were treated for $4 \mathrm{~d}$ with $30 \mu \mathrm{mol}$ of putrescine per rat, the intestinal polyamine levels did not change significantly, as observed in the case of the rats treated with $10 \mu \mathrm{mol}$ per rat. In the rats treated with $2 \mu \mathrm{mol}$ of spermine per rat for $4 \mathrm{~d}$, the intestinal spermine level was significantly higher (increase factor 1.5) than in the control rats, but lower than that observed after treatment with $10 \mu \mathrm{mol}$ per day (increase factor 1.7).

Effects of polyamines or their precursor on the sialylation process of suckling rats. $\alpha$-2,6-Sialyltransferase activity on $N$-glycans in the 14-d-old rats was not modified either by similar amounts $(10 \mu \mathrm{mol}$ per rat) of the polyamines or by ornithine (Fig. $7 A$ ), nor by amounts of polyamines proportional to the weaned rats' consumption (putrescine, $30 \mu \mathrm{mol}$ per rat; spermidine, $10 \mu \mathrm{mol}$ per rat; spermine, $2 \mu \mathrm{mol}$ per rat; data not shown). In the brush-border membranes of the 14-d-old rats treated with $10 \mu \mathrm{mol}$ polyamine per rat, no significant differ-

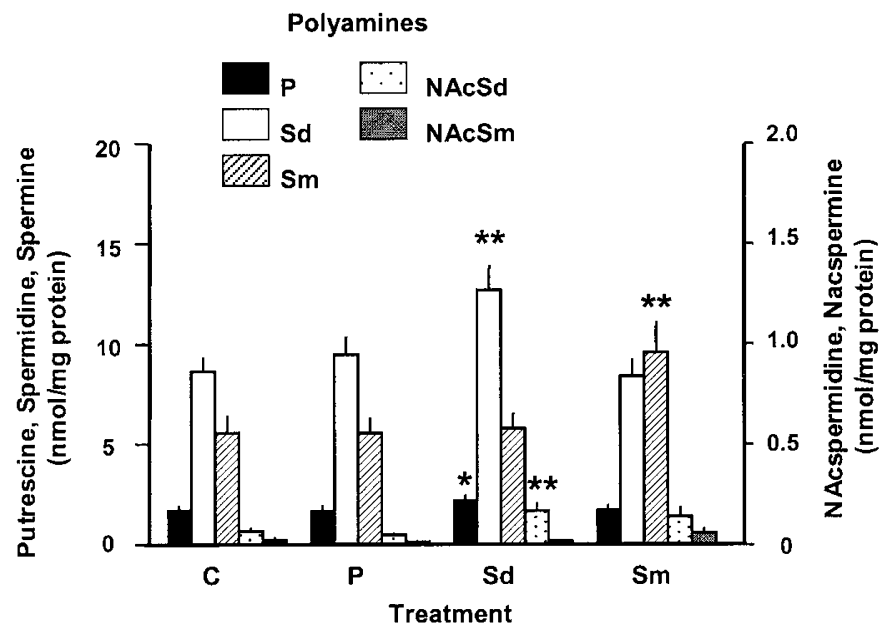

Figure 6. Effects of polyamine treatment on the intestinal polyamine levels of suckling rats. Fourteen-day-old rats were treated orally either with water $(C$, control group) or with similar amounts $(10 \mu \mathrm{mol})$ of each polyamine once a day for $4 \mathrm{~d}$, starting on the 10th day of life. The rats were killed on the 14th day of life, $24 \mathrm{~h}$ after the last ingestion. Polyamine levels were determined by HPLC in the intestinal mucosae from each rat: $P$, putrescine; $S d$, spermidine; $\mathrm{Sm}$, spermine; $\mathrm{NacSd}, \mathrm{N}$-acetylspermidine; $\mathrm{NacSm}, \mathrm{N}$-acetylspermine. Values are mean $\pm \operatorname{SEM}(n=10)$. The results were submitted to a one-factor ANOVA, and the means were compared by the Newman-Keuls test. The assay group values were significantly different from those of the control group $(* p<$ 0.050 , and $* * p<0.020)$.

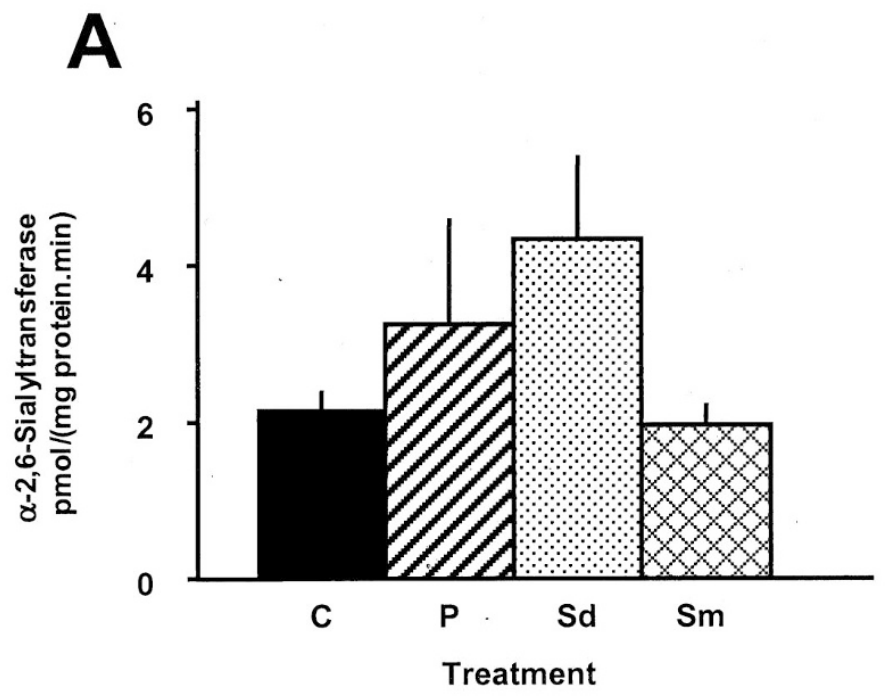

B
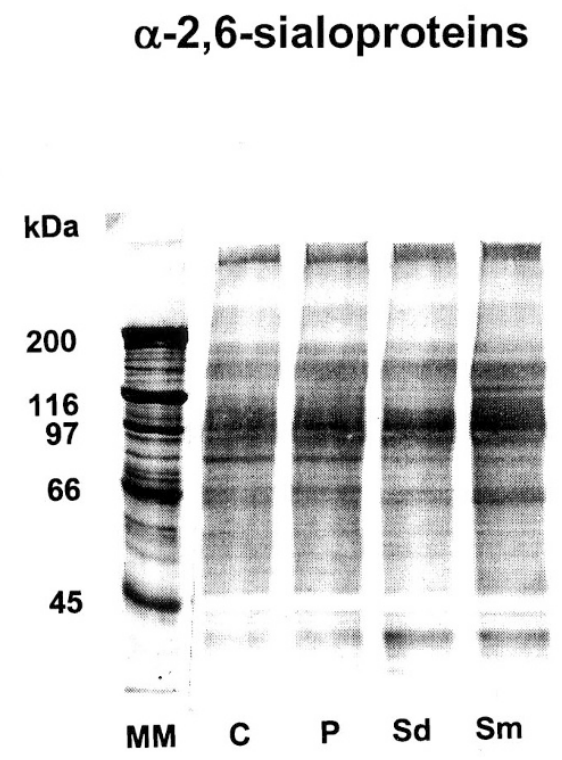

Figure 7. Effects of polyamine treatment on the $\alpha-2,6$-sialylation process in suckling rats. The animals were given either water $(C$, control group) or 10 $\mu \mathrm{mol}$ of each polyamine per rat orally once a day for $4 \mathrm{~d}$, starting on the 10th day of life. $P$, putrescine; $S d$, spermidine; $S m$, spermine. They were killed on the 14th day of life. $A$, for $\alpha$-2,6-sialyltransferase on $N$-glycans, the values were mean $\pm \operatorname{SEM}(n=5)$. The results were submitted to a one-factor ANOVA, and the means were compared by the Newman-Keuls test, which showed no significant change. $B$, detection of $\alpha$-2,6-sialic acid residues in brush-border membrane glycoproteins, after SDS-PAGE (12 $\mu \mathrm{g}$ of proteins/ lane), and transfer onto a nitrocellulose membrane using the specific lectin of Sambucus nigra (SNA). MM, molecular mass control.

ence was observed in the content of the $\alpha$-2,6-sialic acids of glycoproteins by comparison with the control rats (Fig. 7B).

Effects of polyamines or their precursor on the fucosylation process of suckling rats. After treating the suckling rats with similar amounts of either putrescine, spermidine, or spermine (10 $\mu \mathrm{mol}$ per rat per day), membrane-bound $\alpha-1,2-$ fucosyltransferase activity was found to have increase significantly, compared with the control groups. Putrescine had less 
effect (increase factor 1.3) on this activity than spermidine (increase factor 4.7) or spermine (increase factor 4.9; Fig. 8A), and $10 \mu \mathrm{mol}$ of ornithine per rat had no effect (not shown). Similar results were observed with the soluble form of the enzyme. All three polyamines induced significant increases in the mRNA content of the $\alpha-1,2$-fucosyltransferase $F T B$, but at a lower level than that observed for the adult rats (Fig. $8 B$ ). mRNA coding for the $\alpha$-1,2-fucosyltransferase FTA was presently only in small amounts, both in the polyamine-treated and the control rats (not shown).

When the suckling rats were treated for $4 \mathrm{~d}$ with amounts of polyamines proportional to the weaned rats' consumption (30 $\mu \mathrm{mol}$ of putrescine, $10 \mu \mathrm{mol}$ of spermidine, and $2 \mu \mathrm{mol}$ of spermine per rat per day), $\alpha$-1,2-fucosyltransferase activity was also found to be significantly higher than that of the control rats, and the increase factors were fairly similar (2.1 for putrescine, 4.7 for spermidine, 2.0 for spermine), although spermidine was the most active of the three polyamines.

In the suckling rats, fuctinin activity was not modified by polyamine treatments at $10 \mu \mathrm{mol}$ per rat per day (Table 1). Neither GDP-fucose synthesis by epimerase-reductase nor its breakdown by GDP-fucose pyrophosphatase was significantly affected, although $\alpha$-L-fucosidase activity decreased significantly after treatment with $10 \mu \mathrm{mol}$ per rat of spermidine (decrease factor 2.8) or spermine (decrease factor 4.4). But putrescine given at $10 \mu \mathrm{mol}$ per rat had no effect on $\alpha$-Lfucosidase activity. When polyamines were given in proportion to the consumption of the weaned rats $(30 \mu \mathrm{mol}$ of putrescine, $10 \mu \mathrm{mol}$ of spermidine, and $2 \mu \mathrm{mol}$ of spermine per rat per day), $\alpha$-L-fucosidase activity was significantly lowered by similar factors (2.7 for putrescine, 2.8 for spermidine, 3.5 for spermine).

Several $\alpha$-1,2-fucoproteins (similar to those observed after weaning) appeared precociously in the brush-border membranes of the 14-d-old rats treated daily with polyamines at 10 $\mu$ mol per rat, but to different degrees, whereas they were absent in the brush-border membranes of the 14-d-old control rats (Fig. 8C). A fucoprotein with a molecular weight of 100 $\mathrm{kD}$ was particularly clearly detected in all cases, and, at 10 $\mu \mathrm{mol}$ per rat, more fucoproteins appeared after spermine treatment than after putrescine or spermidine treatment. Treatment with putrescine at $30 \mu \mathrm{mol}$ per rat and spermine at $2 \mu \mathrm{mol}$ per rat induced the appearance of $\alpha-1,2$-fucoproteins fairly similar to those observed after spermidine treatment at $10 \mu \mathrm{mol}$ per rat (data not shown).

These results also indicate that the effects of the different polyamines on $\alpha$-1,2-fucosyltransferase and $\alpha$-L-fucosidase activity, and on the $\alpha-1,2$-fucoproteins, are dose-dependent.

\section{DISCUSSION}

Polyamines (putrescine, spermidine, and spermine) are maturation factors for the small intestine and they also play a role in cell differentiation and proliferation. Their endogenous biosynthesis depends, of course, on their precursor (ornithine), but it is generally accepted that the polyamine content of the small intestine as a whole derives largely from exogenous sources such as diet. The aim of the present study was to assess the role
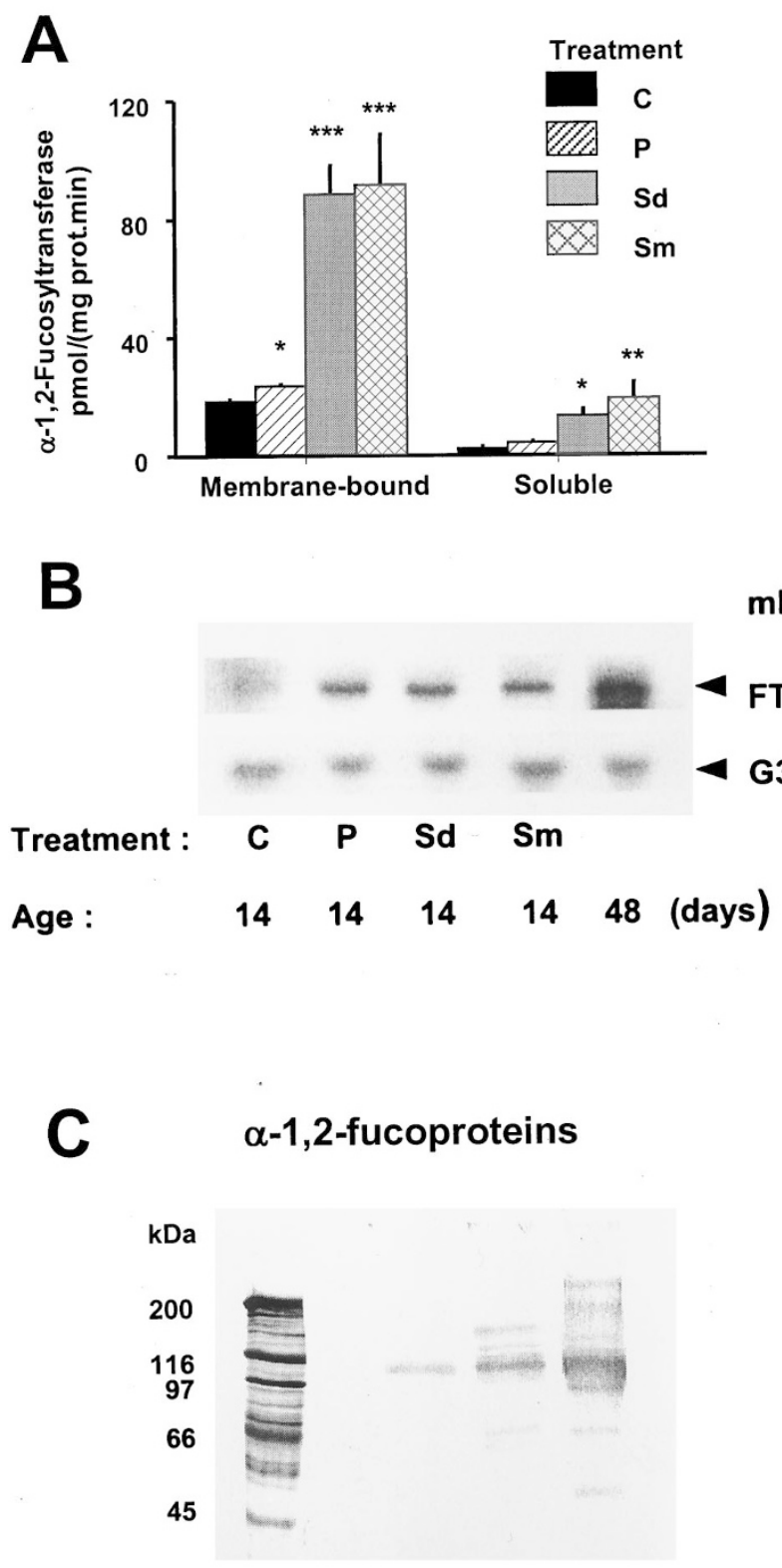

$\begin{array}{lllll}\text { MM } & \text { C } & \mathbf{P} & \text { Sd } & \text { Sm }\end{array}$

Figure 8. Effects of polyamine treatment on the $\alpha$-1,2-fucosylation process in suckling rats. The animals were given water ( $C$, control group) or $10 \mu \mathrm{mol}$ of each polyamine orally once a day for $4 \mathrm{~d}$ starting on the 10th day of life. $P$, putrescine; $S d$, spermidine; $S m$, spermine. They were killed on the 14th day of life. $A, \alpha-1,2$-fucosyltransferase activity in microsomal membranes (membrane-bound) and cytosol (soluble). Values are mean $\pm \operatorname{SEM}(n=8)$. The results were submitted to a one-factor ANOVA and the means were compared by the Newman Keuls test. The values for the assay groups were significantly different from those of the control group $\left({ }^{*} p<0.050,{ }^{*} p<0.020,{ }^{* * *} p<\right.$ $0.001)$. $B$, Northern blots for the determination of $\alpha$-1,2-fucosyltransferase mRNA. $30 \mu \mathrm{g}$ total RNA per group was separated by electrophoresis, then blotted onto a nylon membrane. Hybridization was performed with a cRNA digoxigenin-labeled probe for the $\alpha$-1,2-fucosyltransferase gene $F T B$, and with a G3PDH digoxigenin-labeled cRNA probe used as a control. $C$, detection of $\alpha$-1,2-fucose residues in brush-border membrane glycoproteins, after SDSPAGE ( $8 \mu \mathrm{g}$ of proteins/lane) and transfer to a nitrocellulose membrane, using the specific lectin of Ulex europeus (UEA-I). MM, molecular mass control. 
Table 1. Polyamine effects on the intestinal fucosylation process

\begin{tabular}{|c|c|c|c|c|}
\hline \multirow[b]{2}{*}{ Variable } & \multicolumn{4}{|c|}{ Treatment } \\
\hline & Control & Putrescine & Spermidine & Spermine \\
\hline Fuctinin (U/mg protein) & $375.6 \pm 32.5$ & $485.6 \pm 71.6$ & $291.1 \pm 39.4$ & $331.3 \pm 43.6$ \\
\hline Pyrophosphatase $\left(\mathrm{pmol} \cdot \mathrm{mg}\right.$ protein $\left.{ }^{-1} \cdot \min ^{-1}\right)$ & $499.0 \pm 47.9$ & $578.3 \pm 75.2$ & $585.4 \pm 86.4$ & $412.6 \pm 44.3$ \\
\hline$\alpha$-L-fucosidase $\left(\mathrm{nmol} \cdot \mathrm{mg}\right.$ protein $\left.{ }^{-1} \cdot \min ^{-1}\right)$ & $31.7 \pm 1.7$ & $30.9 \pm 1.7$ & $11.3 \pm 0.8^{*}$ & $7.2 \pm 2.9^{*}$ \\
\hline
\end{tabular}

Animals were given $0.4 \mu \mathrm{mol}$ of each polyamine per gram of body weight or water (control), once a day for $4 \mathrm{~d}$, starting on the 10th day of life. Values are mean \pm SEM (with nine independent determinations for fucosidase, and five for the other types of activity). The results were submitted to a one-factor ANOVA, and the means were compared by the Newman-Keuls test: $* p<0.001$.

of polyamines in the maturation of glycoprotein glycosylation in the rat small intestine. To this end, we first studied the changes that occur in the intestinal polyamine levels during postnatal development, in relation to diet, and, in parallel, changes in the $\alpha-2,6$-sialylation and $\alpha$-1,2-fucosylation of glycoproteins. Then, the effect of polyamines on the glycoprotein maturation process in immature rats was studied.

We found that rat milk contained more spermidine and spermine at the end than at the beginning of lactation, as is the case with human milk $(38,39)$, but that the putrescine level was stable throughout the lactation period. The amounts of polyamine that we found in rat milk were close to those reported in other studies $(38,39)$. When the rats were weaned on Ico, containing higher levels of polyamines than milk, they consumed larger amounts of polyamines. In the small intestine, the levels of spermidine and spermine were significantly higher after weaning, in keeping with the amounts of spermidine and spermine ingested by the rats during this period; they fell off slightly after the 30th day of life. But, in spite of a higher putrescine consumption after weaning than during the lactation period, no increase in intestinal putrescine was observed after weaning. Luk et al. (40) showed temporary increases in intestinal putrescine, spermidine, and spermine around weaning time, followed by rapid decreases toward the basal levels of the suckling rats. But these authors mentioned neither the strain of their rats nor the polyamine composition of the diet at weaning, so the discrepancy between their results and ours is not easily interpretable.

Our results concerning putrescine were unexpected in that we found no particular relationship between the intestinal putrescine content and the amount of putrescine consumed. When similar amounts of putrescine were given orally to the suckling and the weaned rats (in proportion to their weight), putrescine levels increased significantly between 2 and $8 \mathrm{~h}$ after ingestion in the intestines of the suckling rats, although not in weaned rats. These results indicate that putrescine may be assimilated or converted differently by the immature and the mature intestine. The conversion of putrescine to spermidine and spermine had not been shown, irrespective of age. In suckling rats, the putrescine increase was only temporary after putrescine ingestion, whereas the spermidine and spermine levels were still significantly higher $24 \mathrm{~h}$ after the last of four ingestions of spermidine or spermine. The catabolic pathway of putrescine may be more active than those of spermidine and spermine. This hypothesis is supported by Bardocz et al. (41, 42), who have shown that $1 \mathrm{~h}$ after putrescine administration, $80 \%$ had been converted into nonpolyamine metabolites (42), whereas after spermidine or spermine administrations, only 20 to $30 \%$ of these polyamines had been converted into other compounds (41). Putrescine did not seem to be destroyed more quickly in the weaned rats than in the suckling rats, given that diamine oxidase activity was not higher in the weaned rats' intestines than in those of the suckling rats. The lack of increase in putrescine in the small intestine after weaning may also have been related to a difference in putrescine uptake between the immature and the mature intestine, or to its quick release. In the mature intestine, different carriers have been described for putrescine, on the one hand, and spermidine and spermine on the other (43), but they have not been studied during postnatal development. These questions require further study.

Concerning changes in the glycoprotein glycosylation during postnatal development, the activity and mRNA levels of $\alpha$-2,6-sialyltransferase (11), and the amount of $\alpha-2,6$ sialoproteins in the brush-border membranes, were much lower after weaning, whereas the fucosylation level rose after weaning. The correlated rises in the levels of $\alpha-1,2$-fucosyltransferase activity, the mRNA levels of this enzyme's two genes (FTA and FTB), and the amount of fucose linked to glycoprotein glycan chains at the brush-border surface (9) suggest that the increase in intestinal glycoprotein fucosylation during postnatal development is controlled at the level of $\alpha-1,2-$ fucosyltransferase expression. But it is also likely that the fucosylation process is regulated by several other mechanisms, such as the inhibition of fucosyltransferase activity by fuctinin in the immature intestine, and the availability of a substrate, which we have described previously (44). The glycoproteins bound to the brush-border membranes include sucrase and maltase, for which polyamines are maturation factors, and whose activities increase after weaning (23-25). It is possible (although not certain) that the active forms of these enzymes are related to their glycosylation types.

Given the parallel variations that take place during postnatal development between, on the one hand, decreasing putrescine and glycoprotein sialylation levels and, on the other, increasing spermidine and spermine levels and glycoprotein fucosylation, we decided to study the possible role of the different polyamines as maturation factors for the glycoprotein glycosylation process in the intestines of immature suckling rats, by reproducing polyamine levels similar to those observed in the intestines of weaned rats.

Twenty-four hours after oral administration to suckling rats, via oral ingestion, of similar amounts of spermidine or spermine $(10 \mu \mathrm{mol}$ per rat) for $4 \mathrm{~d}$, we found that the intestinal 
spermidine or spermine content had increased to levels similar to those of the weaned rats, as also described by Dufour et al. (23). In our 14-d-old spermidine-treated rats, putrescine and $\mathrm{N}$-acetylspermidine levels also increased, indicating that spermidine is involved in the polyamine-interconversion process, whereas in the spermine-treated rats, there was no interconversion. Nor was any change in the levels of intestinal polyamines observed when the suckling rats were treated for $4 \mathrm{~d}$ with putrescine, either at the same dose or a higher dose $(30 \mu \mathrm{mol}$ per rat), although a transitory increase in the putrescine level was observed between 2 and $8 \mathrm{~h}$ after each ingestion. This result may be related to rapid degradation by diamine oxidase, which was quite active in the 14-d-old rats.

No change was observed in the activity of $\alpha-2,6$ sialyltransferase or in $\alpha$-2,6-sialoproteins in the brush-border membranes after treatment of the 14-d-old rats with any of the three polyamines (irrespective of the dose used), nor with ornithine. But treatment with either spermidine or spermine caused the activity of both soluble and membrane-bound $\alpha$-1,2-fucosyltransferase to increase precociously to levels close to those observed in the weaned rats. The increase in the activity of these enzymes would seem to be related to the transcriptional regulation of $\alpha$-1,2-fucosyltransferase (FTB) expression, given that the mRNA level for the FTB gene increased considerably compared with that of the 14-d-old control rats. The nonmodulation of the FTA gene expression by polyamines raises questions about the linkage specificity of the FTA and FTB genes. These changes, along with stable levels of fuctinin (the fucosyltransferase inhibitor), and substrate (GDPfucose) availability, and a large decrease in $\alpha$-L-fucosidase activity, presumably induced the observed precocious appearance of several $\alpha$-1,2-fucoproteins in the brush-border membrane, which were rather similar to those already observed after weaning (9). One of the $\alpha-1,2$-fucoproteins, with a molecular mass of approximately $100 \mathrm{kD}$, was particularly highly fucosylated. It would be interesting to know the nature of this fucoprotein, as the activity of some glycoprotein digestive enzymes in the brush-border membranes (e.g. sucrase) also increases precociously in the intestine of suckling rats treated with spermidine or spermine in similar conditions (23-26). In rats treated with $10 \mu \mathrm{mol}$ of putrescine per rat for $4 \mathrm{~d}$, the effect of given doses of putrescine on fucosylation was weaker than that of spermidine or spermine (with lesser rises in $\alpha-1,2-$ fucosyltransferase activity and mRNA levels for $F T B$, no effect on $\alpha$-L-fucosidase, and a lesser increase in $\alpha-1,2$-fucoprotein levels). This was probably because of the fact that intestinal putrescine increased only temporarily (for a few hours) after each ingestion. The effect of polyamines on fucosylation $(\alpha-$ 1,2-fucosyltransferase, $\alpha$-L-fucosidase, $\alpha$-1,2-fucoproteins) was dose-dependent, as has also been shown by Buts et al. (37) for some digestive enzymes. When each of the three polyamines was given orally for $4 \mathrm{~d}$ to the suckling rats at a level proportional to the amount ingested by the weaned rats fed on Ico (putrescine at $30 \mu \mathrm{mol}$ per rat, spermidine at $10 \mu \mathrm{mol}$ per rat, and spermine at $2 \mu \mathrm{mol}$ per rat), the decrease in $\alpha$-Lfucosidase activity and the increases in $\alpha$-1,2-fucosyltransferase activity and $\alpha-1,2$-fucoproteins induced by the three polyamines were more similar than at a dose of $10 \mu \mathrm{mol}$ per rat. Of the three polyamines, however, it would seem that spermidine is always the most active and putrescine the least active in inducing a precocious maturation of the fucosylation process.

The mechanism by which polyamines induce premature increases in the $\alpha-1,2$-fucosylation process in suckling rats is not yet clearly understood. After their uptake by enterocytes, polyamines may act directly on their own. Polyamine-protein interactions between the positive charges of spermine and the negative charges of acidic amino-acids have been described for the polyamine binding sites of some enzymes (45). But it seems unlikely that polyamines have a direct effect on the $\alpha$-1,2-fucosyltransferase protein, because polyamines do not modify enzyme activity when added to an acellular medium in vitro (unpublished data). Because of their positive charges, polyamines bind to nuclear macromolecules and modulate DNA transcription in intestinal cells $(46,47)$, and this could partly explain the fact that two polyamines (spermidine and spermine) are more active than putrescine in regulating the expression of the $\alpha$-1,2-fucosyltransferase gene FTB at transcriptional level. However, it is not yet known whether $\alpha-1,2-$ fucosyltransferase activity is modified by combinations of a nuclear protein factor and a polyamine-responsive-element, to which transcription factors bind, as described for some enzymes (48). The weaker effect of putrescine than the other polyamines could also be related to its rapid breakdown by diamine oxidase, whose level of activity is particularly high at $14 \mathrm{~d}$ of age. In addition to their possible direct effects, the polyamines may also indirectly stimulate the secretion of hormones or other secondary effectors. We have previously shown that fucosyltransferase activity in suckling rats is sensitive to glucocorticoids (19), and it has been suggested that spermine can affect ACTH and corticosterone secretion, probably by stimulating the release of gastrointestinal hormones (49) or through a cytokine-dependent mechanism (50). These points require further study.

In conclusion, the present study indicates that the sialylation and fucosylation of intestinal glycoproteins in the rat are differently regulated in the small intestine, as the treatment of suckling rats with polyamines induces a precocious maturation of glycoprotein fucosylation, but not sialylation. When given to suckling rats, both spermidine and spermine (normally found in the small intestine at a higher level after weaning than weaning) reproduced the effects of weaning (high intestinal levels of spermidine and spermine, and increased fucosylation). Putrescine was less effective probably owing to its breakdown. Spermidine and spermine are maturation factors for many glycoproteins of the brush-border membrane, both in terms of enzyme activity (sucrase and maltase) and in terms of fucosylation of their glycan chains. Thus, postnatal changes in intestinal glycoprotein fucosylation could be partly caused by an increase in polyamine intake (and particularly that of spermidine and spermine) at weaning time, which may be important in establishing the barrier function and in triggering digestive enzyme activity.

Acknowledgments. The authors thank Dr. J.P. Piau and Dr. J. LePendu (Unité INSERM U 419, University of Nantes) for 
their generous gift of cDNA fragments for FTA and FTB $\alpha$-1,2-fucosyltransferase. We also thank Dr. D. RuggieroLopez (Unité mixte LIPHA-INSERM U 352, INSA Lyon) for his help in the quantification of Northern blots.

\section{REFERENCES}

1. Steege JC, Buurman WA, Forget PP 1997 The neonatal development of intraepithelial and lamina propria lymphocytes in the murine small intestine. Dev Immunol 5:121128

2. Henning SJ 1981 Postnatal development: coordination of feeding, digestion and metabolism. Am J Physiol 241:G199-G214

3. Shub MT, Pang KY, Swann DA, Walker WA 1983 Age-related changes in chemical composition, physical properties of mucus glycoproteins from the rat small intestine. Biochem J 215:405-411

4. Iiboshi Y, Nezu R, Khan J, Chen K, Cui L, Yoshida H, Wasa M, Fukuzawa M, Kamata S, Takagi Y, Okada A 1996 Developmental changes in distribution of the mucous gel layer and intestinal permeability in rat small intestine. J Parenteral Enteral Nutr 20:406-411

5. Pang KY, Bresson JL, Walker WA 1983 Development of the gastrointestinal mucosal barrier: evidence for structural differences in microvillus membranes from newborn and adult rabbits. Biochim Biophys Acta 727:201-208

6. Van Elburg RM, Uil JJ, De Monchy JG, Heymans HS 1992 Intestinal permeability in pediatric gastroenterology. Scand J Gastroenterol Suppl 194:19-24

7. Torres-Pinedo R, Mahmood A 1984 Postnatal changes in biosynthesis of microvillus membrane glycans of rat small intestine. I. Evidence of a developmental shift from terminal sialylation to fucosylation. Biochem Biophys Res Commun 125:546-553

8. Taatjes DJ, Roth J 1990 Selective loss of sialic acid from rat small intestinal epithelial cells during postnatal development: demonstration with lectin-gold techniques. Eur J Cell Biol 53:255-266

9. Ruggiero-Lopez D, Lenoir D, Louisot P, Biol MC 1995 Developmental changes in intestinal glycosylation: nutrition-dependent multi-factor regulation of the fucosylation pathway at weaning time. Biochim Biophys Acta 1234:29-36

10. Biol MC, Lenoir D, Louisot P 1993 Developmental changes in intestinal glycoprotein glycosylation. Glycoconj J 10(4):247

11. Vertino-Bell A, Ren J, Black JD, Lau JTY 1994 Developmental regulation of $\beta$-galactoside- $\alpha(2-6)$-sialyltransferase in small intestine epithelium. Dev Biol 165:126-136

12. Chu SW, Walker WA 1986 Developmental changes in the activities of sialyl- and fucosyl-transferases in rat small intestine. Biochim Biophys Acta 883:496-500

13. Biol MC, Martin A, Richard M, Louisot P 1987 Developmental changes in intestinal glycosyl-transferase activities. Pediatr Res 22:250-256

14. Nsi-Emvo E, Launay JF, Raul F 1987 Is adult-type hypolactasia in the intestine of mammals related to changes in the intracellular processing of lactase? Cell Mol Biol 33:335-344

15. Büller HA, Rings EH, Pajkrt D, Montgomery RK, Grand RJ 1990 Glycosylation of lactase-phlorizin hydrolase in rat small intestine during development. Gastroenterology 98:667-675

16. Hauri HP, Roth J, Sterchi EE, Lentze MJ 1985 Transport to cell surface of intestinal sucrase-isomaltase is blocked in the Golgi apparatus in a patient with congenital sucrase-isomaltase deficiency. Proc Natl Acad Sci USA 82:4423-4427

17. Henning SJ, Leeper LL 1982 Coordinate loss of glucocorticoid responsiveness by intestinal enzymes during postnatal development. Am J Physiol 242:G89-G94

18. Buts JP, De Keyser N, Kolanowsky J, Van Hoof F 1990 Hormonal regulation of the rat small intestine: responsiveness of villus and crypt cells to insulin during the suckling period and unresponsiveness after weaning. Pediatr Res 27:161-164

19. Biol MC, Lenoir D, Hugueny I, Louisot P 1992 Hormonal regulation of glycosylation process in rat small intestine: responsiveness of fucosyltransferase activity to hydrocortisone during the suckling period, unresponsiveness after weaning. Biochim Biophys Acta 1133:206-212

20. Mahmood A, Torres-Pinedo R 1985 Effect of hormone administration on the sialylation and fucosylation of intestinal microvillus membrane of suckling rats. Pediatr Res 19:899-902

21. Hamr A, Delannoy P, Verbert A, Kolinska J 1997 The hydrocortisone-induced transcriptional down-regulation of $\beta$-galactoside $\alpha$-2,6-sialyltransferase in the small intestine of suckling rats is suppressed by mifepristone (RU-38.486). J Steroid Biochem Mol Biol 60:59-66

22. Biol MC, Lenoir D, Greco S, Galvain D, Hugueny I, Louisot P 1998 Role of insulin and nutritional factors in intestinal glycoprotein fucosylation during postnatal development. Am J Physiol 275:G936-G942
23. Dufour C, Dandrifosse G, Forget P, Vermesse F, Romain N, Lepoint P 1988 Spermine and spermidine induce intestinal maturation in the rat. Gastroenterology 95:112-116

24. Wild GF, Daly AS, Sauriol N, Bennett G 1993 Effect of exogenously administered polyamine on the structural maturation and enzyme ontogeny of the postnatal rat intestine. Biol Neonate 63:246-257

25. Kaouass M, Deloyer P, Dandrifosse G 1994 Intestinal development in suckling rat: direct or indirect spermine action? Digestion 55:160-167

26. Capano G, Bloch KJ, Schiffrin EJ, Dascoli JA, Israel EJ, Harmatz PR 1994 Influence of the polyamine, spermidine, on intestinal maturation and dietary antigen uptake in the neonatal rat. J Pediatr Gastroenterol Nutr 19:34-42

27. Pegg AE, McCann PP 1982 Polyamine metabolism and function. Am J Physiol 243:C212-C221

28. Peulen O, Pirlet C, Klimek M, Goffinet G, Dandrifosse G 1998 Comparison between the natural postnatal maturation and the spermine-induced maturation of the rat intestine. Arch Physiol Biochem 106:46-55

29. Ter Steege JCA, Buurman WA, Forget PP 1997 Spermine induces maturation of the immature intestinal immune system in neonatal rats. J Pediatr Gastroenterol Nutr 25:332-340

30. Kessler MO, Acuto O, Storelli C, Murer H, Muller M, Semenza G 1978 A modified procedure for the rapid determination of efficiently transporting vesicles from small intestinal brush-border membranes. Biochim Biophys Acta 506:136-154

31. Lowry OM, Rosebrough NJ, Farr AL, Randall RJ 1951 Protein measurement with the Folin phenol reagent. J Biol Chem 93:265-275

32. Schaffner W, Weissmann C 1973 A rapid sensitive method for determination of proteins in dilute solution. Anal Biochem 193:502-514

33. Greco S, Hugueny I, George P, Perrin P, Louisot P, Biol MC 2000 Influence of spermine on intestinal maturation of the glycoprotein glycosylation process in neonatal rat. Biochem J 345:69-75

34. Chomczynski P, Sacchi N 1987 Single step method of RNA isolation by acid guanidinium thiocyanate-phenol-chloroform extraction. Anal Biochem 162:156-159

35. Piau JP, Labarriere N, Dabouis G, Denis MG 1994 Evidence for two distinct $\alpha(1,2)$-fucosyltransferase genes differentially expressed throughout the rat colon. Biochem J 300:623-626

36. Kobata A $1982 \alpha$-L-Fucosidase from almond emulsin.Methods Enzymol 83:625-631

37. Buts JP, De Keyser N, Kolanowski J, Sokal E, Van Hoof F 1993 Maturation of villus crypt cell functions in rat small intestine: role of dietary polyamines. Dig Dis Sci 38:1091-1098

38. Pollack PF, Koldovsky O, Nishioda K 1992 Polyamines in human and rat milk and in infant formulas. Am J Clin Nutr 56:371-375

39. Romain N, Dandrifosse G, Jeusette F, Forget P 1992 Polyamine concentration in rat milk and food, human milk and infant formulas. Pediatr Res 32:58-63

40. Luk GD, Marton IJ, Baylin SB 1980 Ornithine decarboxylase is important in intestinal mucosal maturation and recovery from injury in rats. Science 210:195-198

41. Bardocz S, Duguid TI, Brown DS, Grant G, Pusztai A, White A, Ralph A 1995 The importance of dietary polyamines in cell regeneration and growth. Br J Nutr 73:819828

42. Bardocz S, Grant G, Brown DS, Pusztai 1998 Putrescine as a source of instant energy in the small intestine of the rat. Gut 42:24-28

43. Kumagai J, Jain R, Johnson LR 1989 Characteristics of spermidine uptake by isolated rat enterocytes. Am J Physiol 256:G905-G910

44. Ruggiero-Lopez D, Biol MC, Louisot P, Martin A 1991 Participation of an endogenous inhibitor of fucosyltransferase activities in the developmental regulation of intestinal fucosylation processes. Biochem J 279:801-806

45. Leroy D, Fihol O, Delcros JC, Pares S, Chambaz EM, Cochet C 1997 Chemical features of the protein kinase CK2 polyamine binding site. Biochemistry $36: 1242$ 1250

46. Patel AR, Wang JY 1999 Polyamine depletion is associated with an increase in JunD/AP-1 activity in small intestinal crypt cell. Am J Physiol 276:G441-G450

47. Pignata S, Di Luccia A, Lamanda R, Menchise A, D'Agostino L 1999 Interaction of putrescine with nuclear oligopeptides in the enterocyte-like Caco-2 cells. Digestion 60:255-261

48. Wang Y, Xiao L, Thiagalingam A, Nelkin BD, Casero Jr RA 1998 The identification of a cis-element and a trans-acting factor involved in the response to polyamines and polyamine analogues in the regulation of the human spermidine/spermine $\mathrm{N1}$ acetyltransferase gene transcription. J Biol Chem 273:34623-34230

49. Kaouass M, Sulon I, Dandrifosse G 1994 Spermine-induced precocious intestinal maturation in suckling rats: possible involvement of glucocorticoids. J Endocrinol 141:279-283

50. Kaouass M, Deloyer P, Gouders I, Peulen O, Dandrifosse G 1997 Role of interleukin$1 \beta$, interleukin- 6 and TNF- $\alpha$ in intestinal maturation induced by dietary spermine in rats. Endocrine 6:187-194 